\title{
Procedimentos éticos do resgate tipográfico no design de tipos
}

Érico Lebedenco é designer gráfico e de tipos, Especialista em Tipografia pelo Senac SP e Mestrando em Design no PPG Design da Universidade Anhembi Morumbi.

<ericolebedenco@gmail.com> ORCID: 0000-0001-9285-0210
Resumo Este artigo aborda a prática do resgate tipográfico como exemplo significativo da apropriação no design de tipos. Essa prática é analisada por um viés ético na sua conduta profissional, com enfoque nos métodos de produção, identificação de autoria, registro e distribuição de fontes digitais. Investigam-se os principais conflitos éticos a partir dos artigos de Vanderlans (1996) e Downer (1996), identificando os limites da apropriação aceitos na tipografia, juntamente com as interpretações que a autoria, o registro legal e o direito comercial podem apresentar. A consulta aos códigos de ética de associações profissionais oferecem orientações em relação à responsabilidade social e profissional do designer, em convergência com os preceitos da propriedade intelectual aplicados ao design de tipos, observados sob o ponto de vista jurídico por Andrade Lima (2006) e Barroca (2008). Ao final, é definido um conjunto de apontamentos para o comportamento ético na produção de fontes digitais de resgate tipográfico.

Palavras chave Design de tipos, Tipografia, Resgate tipográfico, Ética. 
Gisela Belluzzo de Campos desenvolve pesquisas nas áreas de design gráfico e arte contemporânea, com foco nas questões da linguagem visual. É professora titular do Programa de Pós-Graduação em Design - Mestrado e Doutorado da Universidade Anhembi Morumbi (São Paulo). Doutora e Mestre em Comunicação e Semiótica pela Pontifícia Universidade Católica de São Paulo (PUCSP). Realizou doutorado complementar na École des Hautes Etudes en Sciences Sociales (EHESS, Paris, França), com pesquisa sobre Arte Minimalista; Pós-doutorado na Universidade de Buenos Aires, sobre o campo expandido do Design Gráfico Contemporâneo. Lidera o Grupo de Pesquisa: Design Gráfico Contemporâneo: Linguagens e Interfaces (CNPQ) e atua principalmente nos temas: linguagem gráfica e design; arte contemporânea: inter-relação entre discursos teóricos, processos e procedimentos. <giselabelluzzo@uol.com.br> ORCID: 0000-0002-5743-1093

\section{Ethical procedures of type revival in type design}

Abstract This paper examines the practice of type revival as a significant example of appropriation in type design. The practice is analyzed by an ethical bias in the professional approach, with focus on methods of production, authorship, registration and distribution of digital fonts. The investigation of the main ethical conflicts are based on articles by Vanderlans (1996) and Downer (1996), identifying the limits of appropriation accepted in typography, alongside with the interpretations of authorship, legal registration and commercial law may have. The consultation of moral codes from professional associations provides guidelines regarding the social and professional responsibility of the designer, in accordance with the precepts of intellectual property applied to type design, observed from the legal point of view by Andrade Lima (2006) and Barroca (2008). At the end, it is defined a set of notes for the ethical behavior in the production of digital fonts of type revival.

Keywords Type design, Typography, Type revival, Ethics. 


\section{Introdução}

Neste estudo são discutidas questões éticas relacionadas à pratica do resgate tipográfico no design de tipos, visando à contribuição para um comportamento profissional na produção de fontes digitais dessa natureza. Esta análise tem pertinência com a pesquisa em desenvolvimento por um dos autores deste estudo, no contexto do mestrado em design, que visa à compreensão dos aspectos conceituais e metodológicos do resgate tipográfico.

Dentre os vários entendimentos de moral e sistemas éticos existentes, este estudo aborda a delimitação da ética profissional. Arthur Gianotti (1992) observa que cada grupo social ou profissional tem sua identidade assegurada por normas consentidas, cuja infração provoca censura e até mesmo exclusão. Os indivíduos participantes encontram um espaço para definir suas normas, que valem na medida em que asseguram o respeito mútuo, com critérios para juízo moral encontrados na própria prática, consolidados pelas instituições ou personalidades de renome que amparam. Novaes (1992) reconhece que a evolução do pensamento iluminista e os ideais modernos retiraram a ideia de felicidade existente nas linhas filosóficas clássicas de ética e consolidaram as noções de obrigação, dever e obediência. O desaparecimento de um modelo de virtude opcional e o surgimento das normas éticas e dos preceitos que se devem obedecer foram incorporadas à sociedade. Em muitos casos, as normas setoriais convencionadas em uma classe profissional são asseguradas por outros sistemas normativos mais amplos; como os mecanismos jurídicos do Direito, que atribuem valores, direitos e deveres na relação entre indivíduos e do indivíduo com a sociedade (ANDRADE LIMA, 2006).

A introdução do computador no campo profissional do design durante os anos 1980 produziu um efeito democratizante nas práticas do design gráfico e revolucionou o modo como os tipos eram criados e comercializados. $\mathrm{O}$ novo equipamento promoveu a intangibilidade dos recursos e a rapidez, ao mesmo tempo em que proporcionou a intensificação de conflitos éticos presentes no design e na tipografia. Os caracteres tipográficos deixaram de ser objetos tridimensionais ou matrizes fotográficas, que deveriam ser utilizados em complexas máquinas para composição e impressão de textos, e se transformaram em arquivos de dados eletrônicos - as fontes digitais, contendo um amplo conjunto de instruções para a sua correta reprodução (LEBEDENCO e NEDER, 2016).

A tipografia é uma das principais áreas do design gráfico, com recursos constantemente explorados na comunicação. É considerada um conjunto de práticas e de processos envolvidos na criação e na utilização de símbolos ortográficos e para-ortográficos para fins de reprodução (FARIAS, 2001). A área específica da tipografia que lida com as práticas e os processos para criação de tipos é conhecida como design de tipos. Neste artigo, além dos processos de desenho dos caracteres, também se consideram as práticas para a sua implementação, viabilizando o uso como ferramenta de trabalho pelo designer gráfico. 
Vanderlans (1996) aponta que a transformação tecnológica promovida pelo uso do computador não foi somente positiva, pois aumentou significativamente a quantidade de cópias indevidas, as alterações de design, as atribuições ilegítimas e as distribuições não autorizadas de fontes digitais. Atualmente, ainda se identificam muitas dúvidas em relação ao comportamento ético na atuação do designer, e muitos profissionais desconhecem as limitações jurídicas das suas práticas e da comercialização do seu objeto de trabalho (DIACRITICO, 2016). Frequentemente o discurso da apropriação é utilizado para justificar atitudes no processo de criação de fontes; entretanto, deve-se compreender como este recurso se relaciona com a ideia de autoria no campo profissional (DOWNER, 1996).

O uso intenso da apropriação no resgate tipográfico, dentre as práticas existentes no design de tipos, mostra-se relevante no estudo. Essa prática é compreendida como a recuperação da representação visual dos caracteres tipográficos, de um outro momento histórico e de uma tecnologia considerada obsoleta, para um sistema tecnológico atual, de modo a possibilitar o seu reconhecimento e o seu uso contemporâneo (LEBEDENCO e NEDER, 2016; LO CELSO, 2000). Apesar do resgate tipográfico ser recorrente na tipografia, são poucas as publicações que abordam o tema com a devida relevância ${ }^{1}$. A ausência de convenções metodológicas e a carência de informações possibilitam atitudes equivocadas entre designers, intensificando a desinformação na área. Acredita-se que esclarecimentos de um ponto de vista ético podem contribuir para o incremento desta prática, paralelamente com outras pesquisas acerca dos aspectos metodológicos.

Para se obter um entendimento ético na produção de fontes digitais de resgate tipográfico, são identificados, em um primeiro momento, os principais pontos de conflito ético na tipografia. Destacam-se as abordagens técnicas, os métodos e a identificação de autoria observados principalmente por Downer (1996), Lilie (2013) e Vanderlans (1996) - designers responsáveis por importantes contribuições para o campo. Também se problematiza o recurso da apropriação no design de tipos a partir de um ponto de vista profissional prático, abordando as suas percepções na arte e no design com Argan (1992), Cauduro (2008) e Poynor (2010). Em seguida, as informações coletadas são relacionadas com as normas profissionais estabelecidas no campo do design, apresentadas nos códigos de ética e estatutos de importantes associações da categoria, como ADG Brasil (2004), ATypI (2004), Ico-D (2011) e SOTA (2017). Posteriormente, são examinados os mecanismos de proteção intelectual na legislação brasileira sob a ótica do design segundo Andrade Lima (2006) e Barroca (2008), para compreender a sua aplicabilidade como recurso normativo na tipografia. Por fim, são elencados apontamentos para orientar o comportamento ético na prática profissional do resgate tipográfico e melhorar a relação entre profissionais, clientes e sociedade. 


\section{Conflitos éticos no resgate tipográfico}

Para abordar os conflitos éticos existentes na prática do resgate tipográfico, é necessário, primeiramente, esclarecer pontos importantes da influência digital no campo da tipografia. Antes da introdução do computador no design, os tipos eram vendidos apenas para as gráficas e oficinas especializadas que produziam os projetos; assim, a utilização dos tipos ou equipamentos era limitado aos profissionais do setor (ROCHA, 2012; VANDERLANS, 1996). Todavia, o computador pessoal possibilitou que cada usuário se tornasse um potencial comprador de fontes digitais. Softwares gráficos e sistemas operacionais passaram a oferecer cada vez mais alternativas de tipos para a criação de layouts, sem a dependência das gráficas. $O$ computador ampliou a demanda tipográfica e simultaneamente possibilitou que as fontes fossem produzidas com tempo e recursos menores, diminuindo as etapas de trabalho e os profissionais envolvidos (VANDERLANS, 1996; GOMES, 2010).

Para Gomes (2010), as tecnologias digitais permitiram que o processo produtivo de um projeto tipográfico fosse retomado pelo designer com o mesmo aparato tecnológico utilizado por empresas especializadas. Ao mesmo tempo, os questionamentos acerca dos cânones modernos produziam uma reavaliação intelectual da natureza do design como ofício. Repúdio às regras, abordagens não canônicas e métodos alternativos de trabalho foram cada vez mais adotados pelos designers gráficos e, consequentemente, também pelos designers de tipos. (POYNOR, 2010; VILLAS-BOAS, 2007). Neste período de pós-modernismo, Poynor $(2010$, p.12) observa que no design "a originalidade no sentido modernista imperativo de 'fazer o novo', deixa de ser o objetivo; há uma proliferação da paródia, do pastiche e da reciclagem irônica de velhas formas". São encaradas novas maneiras de se fazer design, com maior flexibilidade metodológica, viabilizadas com o crescente avanço da tecnologia.

Apesar da grande liberdade oferecida pelas ferramentas digitais e pelos novos ideais no design, a atividade do designer continua sendo um ofício sistematizado por normas profissionais da classe, padrões técnicos de mercado e leis que regulam a relação de trabalho e a prestação de serviços na sociedade. Por isso, são identificados a seguir alguns métodos, abordagens e conceitos pertinentes à produção de fontes digitais de resgate tipográfico que podem gerar conflitos éticos.

Ao estudar a aplicação de copyright na tipografia, Lilie (2013) observa que algumas pessoas defendem a cópia irrestrita de tipos, de origem histórica ou não, alegando que as formas das letras são universais e, por isso, seriam livres de qualquer registro. De fato, os arquétipos estruturais abstratos das letras do alfabeto latino existem há muito tempo e servem como base para toda a construção dos caracteres tipográficos. Porém, qualquer obra produzida pelo intelecto humano é protegida por direito autoral, sendo ele moral e patrimonial. A aplicabilidade das normas de propriedade intelectual no design de tipos ainda será abordada com maior detalhamento neste estudo, mas deve-se destacar por ora que, independente do aspecto 


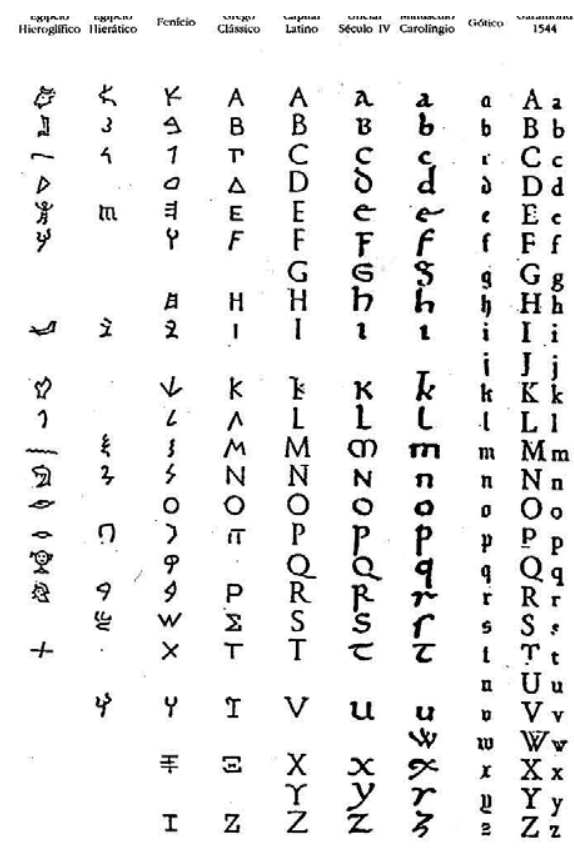

Fig 1. Evolução do alfabeto latino Fonte: anakabum.wordpress.com (2017) financeiro que possa existir, um indivíduo tem assegurado o direito moral de ser identificado como autor de sua obra, seja ela derivativa ou não (ANDRADE LIMA, 2006; DIACRITICO, 2016).

Avançando a reflexão sobre cópia, Vanderlans (1996) reconhece a existência de sampling na tipografia, que se trata da produção de tipos novos com o uso de amostras ou o redesenho dos elementos formais existentes em outros tipos. Prática favorecida com o uso do computador, pois esse mecanismo permite a cópia precisa a partir de fontes já disponíveis. Não é uma ideia recente na tipografia, afinal a cópia de elementos gráficos ou modelos de letras é intrínseca ao design de tipos, visto que as estruturas dos caracteres tipográficos, consolidadas ao longo dos séculos, são herança dos modelos apresentados nos manuais de escrita (figura 2). Gomes (2010) observa que a apropriação de referências visuais preexistentes é uma prática que se tornou comum na tipografia desde o Renascimento. Dessa forma, se reconhece que muito progresso técnico-formal realizado neste campo foi resultado da adaptação de tipos ou de ajustes formais em letras para atender novas necessidades na sociedade (DOWNER, 1996; VANDERLANS, 1996).

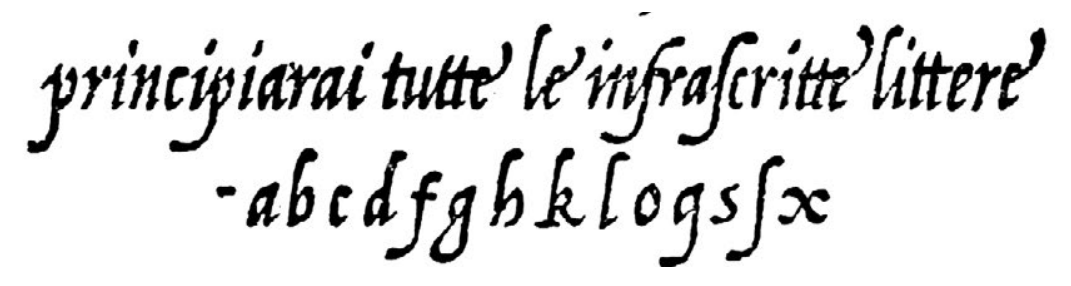

Fig 2. Modelo de escrita cursiva chanceleresca que foi a base para a construção dos tipos itálicos de Aldus Manutius e Francesco Griffo no início do século XVI

Fonte: Detalhe de "La Operina“ (ARRIGHI, 1524). https://archive.org/details/laoperinadiludou00arri (2018)

Entretanto, deve-se questionar se há diferença entre o ato de copiar as informações digitais de fontes disponíveis e copiar um modelo histórico redesenhando-o a partir de impressos. Obviamente o processo analógico favorece alterações sutis no design, mesmo não intencionais, enquanto a cópia digital é feita integralmente de uma fonte na mesma tecnologia. Esse procedimento digital está distante da prática profissional estabelecida no mercado pela possibilidade de violação dos direitos autorais, sendo reconhecida em muitos países como uma infração da lei ${ }^{2}$. No caso do resgate tipográfico, é necessário que exista o distanciamento histórico e tecnológico entre o tipo original e a sua nova versão. Copiar informações de uma fonte digital, mesmo que baseada em um modelo histórico, não é executar um resgate, mas realizar um ato questionável que Vanderlans (1996) identifica como uma forma de pirataria. 
É importante ressaltar que o mencionado distanciamento histórico entre o original e o seu resgate é mais do que somente um dos aspectos conceituais na definição apropriada da prática (LEBEDENCO e NEDER, 2016). A existência de um grande intervalo de tempo entre a produção dos tipos pode auxiliar na observância das normas de direitos autorais e domínio público, regulados no Brasil pela Lei no 9.610/98, cujo artigo 41 informa que "os direitos patrimoniais do autor perduram por setenta anos contados de 10 de janeiro do ano subsequente ao de seu falecimento, obedecida a ordem sucessória da lei civil (ANDRADE LIMA, 2006, p. 137)". O designer que pretende realizar um resgate tipográfico deve conhecer as implicações das normas de propriedade intelectual existentes no design de tipos, como será apresentado mais detalhadamente neste artigo.

No mercado de fontes digitais, observa-se uma grande oferta de tipos com aspectos formais semelhantes ou mesmo com nomes similares, em virtude da alta reputação adquirida ao longo do século XX pela ideia de tipos clássicos revisitados, o que torna esta abordagem projetual uma atividade lucrativa para as empresas (LO CELSO, 2000). As incontáveis Garamonds (figura 3) produzidas pela Adobe, Stempel, Monotype, ITC e outras companhias, comprovam esta estratégia comercial; porém, exibem variações formais significativas na construção dos mesmos caracteres tipográficos. Muitos desses tipos são baseados em diferentes modelos das letras do tipógrafo renascentista Claude Garamond, contudo grande parte apresenta características tão distintas das originais - por equívoco ou por uma estratégia intencional - que é difícil classificá-los como tipos Garamond, como é o caso da ITC Garamond (DOWNER, 1996; CARDINALLI, 2004). Tendo em vista esta situação, Downer (1996) recomenda que o designer avalie se a alta recorrência de um estilo ou excesso de um mesmo modelo de letra no mercado enfraqueceria a validade da proposta de resgate tipográfico.

Fig 3. "Garamonds" de Robert Slimbach para Adobe (1988), Fundidora Stempel (1924), Francesco Simoncini (1958), Fritz Max Stelzter para Monotype (1922) e Tony Stan para ITC (1970) Fonte: LO CELSO (2000)
1. Garamond Adobe

2. Garamond Stempel

3. Garamond Simoncini

4. Garamond Monotype
5. Garamond ITC 
É preciso refletir o quanto a aparência original pode ou deve ser alterada para que o designer de tipos se denomine autor da obra resultante. Também é possível indagar se existiria apenas um autor no referido projeto, uma vez que o resgate tipográfico implica em redesenhos, ampliações no conjunto de caracteres, ajustes formais para adequação de uso e adaptações técnicas para diferentes suportes, sem perder a personalidade do original (LO CELSO, 2000; DOWNER, 1996; VANDERLANS, 1996).

Considerando-se o que foi identificado até o momento, percebe-se que a apropriação é um recurso muito usado na tipografia, sendo o resgate tipográfico a sua forma mais explícita. Entretanto, dada a natureza comercial das fontes digitais, faz-se necessário analisar esse procedimento para se compreender os limites de aceitação sem prejuízo às obras originais.

\section{Limites da apropriação na tipografia}

O termo apropriação é empregado principalmente pela história e pela crítica de arte para indicar objetos extra-artísticos, e algumas vezes de outras obras, nos trabalhos de arte. $O$ conceito remete aos procedimentos adotados nas colagens cubistas (ARGAN, 1992) e se trata de uma justaposição ou combinação de elementos distintos para a criação de algo novo. Mesmo que a apropriação retome as experiências realizadas no início do século XX, a popularização do termo refere-se principalmente ao movimento artístico do Pop Art. Certos artistas norte-americanos utilizam outras obras de arte ou imagens de marcas e produtos familiares do cotidiano com o objetivo de criar novas situações e instigar os sentidos com imagens já conhecidas pelo público (CAUDURO, 2008). Deste modo, a apropriação, como um procedimento artístico, coloca em pauta as questões da originalidade, da autenticidade e da autoria da obra de arte, questionando a natureza da arte e sua definição.

No campo do design, a apropriação também foi fonte de debates no final do século XX. O recurso é adotado como uma opção de retórica visual, incorporando imagens bastante conhecidas ou utilizando referências visuais de outros profissionais, de modo a contar com o imaginário coletivo do público para o entendimento da ironia, irreverência ou homenagem feita pelo designer em uma nova obra (CAUDURO, 2008). Para Poynor (2010), a apropriação é um dos temas-chave no design do pós-modernismo com abordagens que se tornaram típicas, ou mesmo tendências estilísticas, envolvendo a imitação ou mímica dos maneirismos de outros estilos e profissionais. $O$ pesquisador distingue algumas destas abordagens como: a paródia, o pastiche, o vernacular, o retrô e o resgatismo.

0 pastiche e a paródia se relacionam enquanto imitação de elementos preexistentes na arte, no design ou em outros nichos culturais, contudo, a paródia incorpora a função de satirizar ou criticar o elemento original adotado. O vernacular, para Poynor (2010), estaria relacionado aos aspectos populares da comunicação visual, com um design que se pretende parecer criado por alguém ignorante das regras estabelecidas no campo. Enquanto 
o vernacular, o pastiche e a paródia se apropriam de estilos anteriores ou contemporâneos, o design retrô sugere a emulação de estilos visuais históricos, muitas vezes do próprio campo do design e das artes, com ares de nostalgia. Por sua vez, o resgatismo - termo cunhado por Garret durante os anos 1990 - também utiliza o passado como fonte de inspiração, no entanto propõe a construção de algo autêntico ao novo momento cultural por meio da resignificação dos elementos visuais aplicados em novos contextos (POYNOR, 2010).

Apesar do recurso da apropriação ser um tema importante no design e na arte pós-moderna, o procedimento não é exclusivo dessa época. Segundo Poynor (2010, p.72) “o design gráfico sempre tomou de empréstimo imagens e abordagens de outros campos, especialmente das belas artes e da cultura popular". Também na tipografia a apropriação é vista como recurso recorrente ao longo de sua história, como indicado por Gomes (2010), Rocha (2012) e Downer (1996). O que difere as apropriações realizadas no final do século XX das suas antecessoras seria, então, a facilidade gerada pela utilização crescente das novas tecnologias digitais materializadas no computador.

Mesmo com o uso da apropriação como reflexão crítica sobre autoria, originalidade e autenticidade entre artistas e designers, a atividade profissional do designer envolve diferentes formas de uso de obras atribuídas a outros autores, como referência ou ferramenta, transformando-as em uma nova obra, geralmente comercial. Desse modo, é importante que o profissional compreenda as implicações das diferentes proteções dadas às obras intelectuais, visando a respeitar as criações alheias e proteger as próprias (ANDRADE LIMA, 2006). A tipografia é vista no campo do design gráfico como uma ferramenta de trabalho que atende funções de comunicação e expressão visual, adquirida por meio de uma licença de uso de fonte digital, de modo similar à aquisição de outros recursos como fotos, ilustrações e gráficos. Assim, dada a natureza comercial das fontes digitais, se faz necessário entender os limites apresentados pela apropriação na tipografia de modo a evitar o plágio, a contrafação e outros problemas possíveis no campo jurídico, sem prejudicar os procedimentos intrínsecos ao design de tipos.

A Lei no 9.610/98 define a contrafação como a reprodução integral ou parcial não autorizada de obra protegida pelo direito autoral e o plágio como a falsa apresentação, utilização ou reivindicação de autoria de obra ou trabalho intelectual, integral ou parcial, produzido por terceiros (ANDRADE LIMA, 2006). A legislação não oferece critérios específicos

para a avaliação do plágio e sua caracterização deve ser avaliada por especialistas; contudo, nem todas as reproduções carecem de autorizações prévias. Andrade Lima (2006) observa que são livres as paráfrases e paródias que não forem reproduções verdadeiras das obras originárias, de modo a não implicarem descrédito.

Downer (1996) reconhece a existência de muitas justificativas para a apropriação enquanto prática regular na tipografia. Dentre elas: a alegação que a apropriação sempre foi executada deste modo no design de tipos; o argumento de que todos na indústria tipográfica trabalham deste modo 
(devido à falta de consenso entre designers e empresas), e que essa prática não é ilegal (com a exceção às proteções aplicadas aos softwares e fontes digitais). Entretanto, se mostra muito crítico ao apontar que, do ponto de vista ético e jurídico, todo trabalho é propriedade de alguém, portanto qualquer forma de omissão a respeito da propriedade intelectual é negligência e desrespeita o esforço de outros profissionais.

Levando-se em consideração que todo indivíduo tem o direito moral de ser reconhecido por sua obra (ANDRADE LIMA, 2006), o discurso de vendas de uma fonte digital não deve induzir a interpretação de ineditismo por omitir referências das obras apropriadas. Tampouco deve omitir os nomes dos profissionais envolvidos no design: integrantes da equipe de trabalho ou a autoria individual de um design preexistente.

Além das implicações de propriedade intelectual que serão abordadas mais à frente, o uso da apropriação na tipografia é problemática porque esse recurso de retórica visual pressupõe o reconhecimento dos elementos constituintes da obra final por meio de um repertório dominado pelo observador (CAUDURO, 2008). Entretanto, nem todos estão aptos tecnicamente para identificar estilos ou aspectos formais particulares aos tipos. Situação complicada, pois muitos dos aspectos construtivos nas formas das letras se tornaram paradigmas no design, sendo reutilizados e adaptados ao longo de toda a história da tipografia. Assim, em muitos casos não é possível definir com exatidão o ineditismo de determinados elementos porque muito do que se desenvolve hoje em dia no design de tipos é baseado em modelos consolidados pelo uso.

Apesar de a apropriação ser bem-vinda enquanto recurso de retórica na arte e em determinados campos do design gráfico (POYNOR, 2010), o contexto no qual ela está sendo tratada aqui apresenta limitações de cunho profissional, já que muitas das obras resultantes no design gráfico e de tipos - neste caso as fontes digitais -, são distribuídas por meio de transações comerciais ou são resultados delas. Deste modo, a influência dos direitos morais e patrimoniais das obras apropriadas devem ser levadas em consideração. Mesmo que não seja possível traçar a autoria de determinados aspectos formais na tipografia, ainda é possível relacioná-los com um período histórico, localização geográfica ou movimento artístico, viabilizando o seu reconhecimento como parte de um patrimônio cultural.

\section{Dificuldades existentes na abordagem profissional}

Para compreender melhor os conflitos éticos encontrados na prática do resgate tipográfico, é necessário analisar algumas dificuldades existentes nas abordagens e métodos utilizados por designers de tipos, em razão da variedade de interpretações que a autoria, o registro legal e o direito de uso comercial podem ter em diferentes circunstâncias.

Vanderlans (1996) observa que copiar e colar partes de fontes para a criação de uma fonte nova (sampled font) atrai jovens designers e pessoas ingênuas que não são do campo do design. $O$ autor considera que esta práti- 
ca pode auxiliar no aprendizado, mas carece de conhecimento técnico e, no caso de uma fonte comercial, demonstraria descaso com o trabalho de terceiros. É importante ressaltar que as leis de copyright de software protegem os arquivos das fontes digitais; entretanto, tipos existentes em tecnologias ultrapassadas apresentam situações diferentes. Por isso, é necessário que os aspectos legais do design original e da sua tecnologia sejam consultados antes da realização de um resgate. Downer (1996) aponta que a consulta às normas para que uma obra entre em domínio público pode oferecer segurança na realização de projetos desta natureza, adotando-se originais com um grande distanciamento histórico.

Existe uma variedade de abordagens na prática do resgate tipográfico que vão desde uma reprodução fiel até a exploração formal do design original. Em todas as possibilidades, o designer de tipos não pode reivindicar a autoria isolada do projeto; pelo contrário, deve deixar explícito quem é o autor do design original que adotou (LEBEDENCO e NEDER, 2016). Omitir ou alterar informações referenciais vai contra o próprio conceito da prática e demostra, em alguns casos, a má-fé de um profissional.

\section{Adobe Caslon Regular Big Caslon Medium LTC Caslon Regular} Williams Caslon Text Regular

Fig 4. Interpretações de "Caslon" por Carol Twombly para Adobe (1990), Matthew Carter (1994), Monotype (2005) e William Bergson (2010) Fonte: $\mathrm{o}$ autor
Para Lebedenco e Neder (2016) a tecnologia original e as amostras consultadas - impressos na sua grande maioria - podem influenciar significativamente o resultado obtido; contudo, o aspecto final do projeto dependerá diretamente das decisões feitas pelo designer com base na interpretação e no conhecimento adquirido sobre o design original. Muitas vezes a reputação de um designer ou tipógrafo está associada ao design original, como Caslon (figura 4), Baskerville e Garamond, para citar alguns dos mais conhecidos. Existe uma grande responsabilidade de quem realiza esta prática para a correta tradução do design, sem prejudicar a qualidade dos tipos 
na nova tecnologia. O resultado será questionável quando não exibir fidelidade às características originais, confundindo usuários comuns e profissionais, e afetando o reconhecimento do design original para novas gerações. Poderá, inclusive, não obter reconhecimento como um resgate tipográfico real, indicando mais preocupação com estratégias de vendas e menos com pesquisa (DOWNER, 1996).

Segundo Downer (1996), a apropriação de um tipo que já foi muito popular apenas como estratégia para ganho financeiro prejudica a prática profissional e o mercado de trabalho. Para o autor, esse comportamento não leva em consideração os benefícios que um tipo pode oferecer para futuras gerações e nem considera a necessidade de recuperar tipos em desuso ou que foram esquecidos nos súbitos avanços tecnológicos da indústria. Ademais, essa atitude ocasiona o surgimento de incontáveis fontes baseadas nos mesmos originais ou similares, competindo com diferentes níveis de qualidade - como as já citadas Garamonds (DOWNER, 1996; CARDINALLI, 2004).

Não há definições claras sobre como lidar com todos os aspectos éticos no resgate tipográfico. Todavia, as atitudes tomadas pelo designer em relação ao trabalho de outros profissionais e o seu papel na sociedade deveriam ser direcionadas de acordo com a ética e as normas de conduta profissional existentes no campo do design (VANDERLANS, 1996). Normas estas, supostamente aprendidas durante a formação do designer e orientadas pelos órgãos ou associações de representação. Dado o papel que as associações profissionais deveriam exercer na regulamentação, são expostas a seguir algumas orientações relevantes para o design de tipos.

\section{Orientações das associações profissionais}

Os códigos ou estatutos das associações profissionais representam, em geral, as práticas recorrentes ou os ideais defendidos no mercado. No caso das associações no campo do design gráfico e da tipografia, esses documentos costumam apresentar orientações de conduta que envolvem tanto as questões legais como, também, as relações profissionais entre designers, fornecedores, clientes e sociedade.

Visto que a tipografia está inserida no campo amplo do design, algumas informações que se referem às práticas profissionais do designer gráfico podem ser adotadas em relação aos designers de tipos. Nesse estudo, foram analisados os estatutos ou códigos de ética existentes em quatro importantes associações profissionais, com representações no Brasil e no exterior, que podem elucidar o que seria um comportamento ético no design de tipos. São elas: Association Typographique Internationale (ATypI), International Council of Design (ICO-D), Associação de Designers Gráficos do Brasil (ADG Brasil) e Society of Typographic Aficionados (SOTA). 
ATypl

A popularização de tipos na sociedade sempre instigou a realização de cópias por empresas e profissionais que concorrem no mercado tipográfico, acarretando que muitos dos aspectos desses tipos se tornaram estilos de época ou gosto comercial. Contudo, a cópia indiscriminada para uso comercial é vista por vários profissionais como pirataria. Por isso, o código de moral da Association Typographique Internationale, The Code Morale, foi uma tentativa de lidar com este paradoxo, sendo a principal razão da criação da associação, por Peignot em 1957 (SMEIJERS, 2003).

Esse código afirma que a associação pretende enfrentar a cópia não autorizada, respeitando as leis de propriedade industrial (copyright) e dar suporte aos princípios éticos e profissionais dos membros. Todavia, em 1986, o código foi questionado por Charles Bigelow, juntamente com vários outros associados. Havia concordância com o código, porém era reconhecida a ineficácia entre as empresas e membros, uma vez que as orientações contra plágio não eram amplamente adotadas (DEVROYE, 2017).

Sendo uma associação de adesão voluntária, a ATypI não possui poder real de regulamentação profissional. Desse modo, após anos de discussões entre membros e diretoria, o estatuto da associação foi revisado e, em 2004, o código de moral foi retirado por "não se adequar mais aos objetivos da associação" (DEVROYE, 2017). Entretanto, alguns objetivos da ATypI (2004) permanecem, dos quais: promover a criação de tipos e obter a proteção legal para a tipografia em forma de leis e acordos internacionais; se opor a cópia não autorizada; garantir a observância das leis de propriedade intelectual, copyright e propriedade industrial entre os membros; dar apoio na criação de um acordo internacional que protegerá designers gráficos e de tipos.

International Council of Design (Ico-D)

A Ico-D, conhecida anteriormente como Icograda, foi fundada em 1963 com a proposta de promover o pensamento, a prática, a educação, a pesquisa e a regulamentação do design. Atualmente, representa mais de 140 associações de design pelo mundo, distribuídas em 67 países (Ico-D, 2011).

A organização orienta o comportamento profissional dos designers gráficos por meio de um código de conduta profissional que foi revisado e publicado em 2011. Dentre as orientações presentes no documento da Ico-D (2011) estão: o designer gráfico possui a responsabilidade de agir para manter a honra e a dignidade da profissão; o designer deve ser justo na crítica e não denegrir a reputação profissional de outro colega designer; o designer não deve aceitar instruções (vindas do cliente) que impliquem em plágio, nem deve conscientemente agir de modo a produzir um plágio; qualquer material de divulgação deve conter apenas fatos e afirmações verídicos, sendo justo para os clientes e outros designers, de acordo com a dignidade da profissão. 


\section{ADG Brasil}

A Associação de Designers Gráficos do Brasil, fundada em 1989, busca a divulgação, a valorização do design gráfico nacional e o aprimoramento profissional dos membros da categoria. Para isso, um dos mecanismos existentes na associação é o seu conselho de ética, direcionado para a orientação, educação e harmonia dos profissionais. Em diversas ocasiões, o conselho emite análises ou opiniões em relação a situações que envolvam a prática do design gráfico na sociedade.

Em 2004, o código de ética da associação foi publicado junto com o seu estatuto, acompanhado de informações frequentemente requisitadas pelos membros. Dentre as orientações para o incremento da prática profissional do design apresentados pela ADG Brasil (2004) estão algumas que se relacionam com as questões levantadas neste estudo: o designer gráfico deve respeitar e fazer respeitar os preceitos internacionais da propriedade industrial; não se aproveitar nem concorrer para que se aproveitem ideias, planos ou projetos de autoria de outros profissionais sem a necessária citação ou autorização expressa destes; não deve reivindicar ter crédito sozinho em um projeto no qual outros designers gráficos colaboraram.

Society of Typographic Afıcionados (SOTA)

A SOTA é uma organização internacional sem fins lucrativos, sediada em Nova York, dedicada ao fomento da tipografia, seu estudo e amparo para os designers de tipos. Essa sociedade é responsável pela organização da conferência TypeCon, uma das principais conferências de tipografia do mundo.

Para dar assistência aos membros, a SOTA possui uma política de direitos autorais em alinhamento com a legislação dos Estados Unidos, juntamente com um setor jurídico que se compromete a lidar com violações de propriedade intelectual e copyright entre seus membros. Esse núcleo de propriedade intelectual é conhecido como Agent for Copyright Notice e apresenta orientações identificadas como DMCA policy: Notice for Claims of Intellectual Property Violations (2017). Para lidar com as infrações são requisitadas provas de autoria, dados pessoais, declaração de responsabilidade e comprovações do uso indevido.

Nesses casos, as ações tomadas pela SOTA (2017) são: sendo comprovada a infração, o membro infrator é expulso da sociedade; um agente de copyright da SOTA auxiliará na solução dos problemas identificados, denúncias e orientará juridicamente os membros prejudicados. 


\section{Aplicabilidade da propriedade intelectual no design de tipos}

Tendo em vista a importância dada pelas associações de design e tipografia para as questões de propriedade intelectual no design, faz-se necessário apresentar algumas noções desse ramo jurídico. Serão apresentados os aspectos básicos e suas relações com o design, seguidos das implicações jurídicas específicas no campo da tipografia.

A propriedade intelectual é o campo jurídico que cuida das criações intelectuais do indivíduo. Andrade Lima (2006) destaca que, desse campo, o design se relaciona com os ramos do direito autoral e da propriedade industrial. o direito autoral, que se divide em direito moral e direito patrimonial, é o direito que o autor tem de gozar dos benefícios resultantes da sua criação. É um preceito constitucional e está regulamentado pela Lei no 9.610/98. O direito moral é um direito personalizado, irrenunciável, intransferível e absoluto do autor, tratando-se da sua identificação pessoal com a obra. Enquanto isso, o direito patrimonial do autor é resultante da publicação da obra pelo próprio autor ou por representante autorizado. Diz respeito ao aspecto monetário da obra intelectual, podendo ser vendido, cedido ou licenciado. $O$ direito patrimonial possui proteção legal por tempo limitado, durando, como regra geral, por toda a vida do autor, acrescidos de 70 anos. Tempo contado a partir de janeiro do ano seguinte ao seu falecimento, sendo obedecida a ordem sucessória estipulada no Código Civil. Considera-se ilegal a reprodução fraudulenta de obra alheia ou a violação de direito moral do autor, que são os já citados crimes de contrafação e plágio (ANDRADE LIMA, 2006; DIACRÍTICO, 2016).

O design também se relaciona com o direito de propriedade industrial, que é um conjunto de princípios reguladores das proteções às criações intelectuais no campo técnico, objetivando a difusão tecnológica e a garantia de exploração exclusiva por parte de seus criadores. Para Andrade Lima (2006), esse é o ramo jurídico que apresenta o maior número de dispositivos relacionados ao campo do design, sendo regulamentado pela Lei no 9.279/96. O direito de propriedade industrial oferece proteção para invenções, modelos de utilidade, desenhos industriais e marcas. Entretanto, especificamente para a tipografia, as categorias de proteção oferecidas apresentam dificuldades para o registro e a proteção dos tipos, como será visto a seguir.

Barroca (2008) observa que o alfabeto pode ser interpretado como um conjunto de sinais de caráter genérico, necessários e comuns no qual pode existir um rearranjo estético no desenho das letras; todavia, é identificado como um conceito. No caso das fontes digitais, sendo o alfabeto um conceito, o objeto no qual se inclui é a própria fonte. De acordo com a legislação brasileira, a fonte não se enquadra nos gêneros de proteção conferidos pela lei de propriedade industrial; não é patenteável e não é possível associá-la aos conceitos de novidade e inventividade descritas na Lei.

Uma dificuldade equivalente à encontrada na legislação dos Estados Unidos, como observado por Yan (2013), cuja revisão do Ato de Copyright de 
1976 revogou o registro de tipos baseado na separação entre elementos que ditam eficiência, funcionalidade e natureza - não registráveis - daquilo que é uma expressão artística - hipoteticamente sujeito à proteção. Contudo, por mais que existam dificuldades jurídicas em identificar o caráter criativo ou de expressão artística no design dos tipos, isso não afasta a proteção autoral do projeto. Barroca (2008) observa que a propriedade sobre o corpo mecânico não deve se confundir com a titularidade da obra, devendo-se ter bem clara esta distinção no caso das fontes digitais. A interpretação da fonte digital no Direito Intelectual permite a separação entre o design dos tipos (enquanto elementos estético-formais das letras) e as fontes digitais (arquivos de dados eletrônicos com instruções para a sua correta reprodução).

Objeto de proteção pela Lei no 9.609/98, software ou programa de computador é elemento que interagindo com a máquina, permite o processamento de informações. Uma de suas categorias é o programa de aplicação, que serve para facilitar a resolução de problemas do usuário, descrição na qual a fonte digital se enquadra (DIACRÍTICO, 2016). Essa possibilidade de proteção gera algumas dificuldades entre os profissionais de design e juristas que lidam com a questão. $O$ design presente em uma fonte digital trata-se de manifestação artística do alfabeto e de interpretação do designer de tipos, de modo suficientemente distintivo para que seja divulgado e comercializado de acordo com estes aspectos visuais. Logo, a falta de proteção do design é interpretada por alguns profissionais como uma anomalia, já que este trabalho apresenta um esforço criativo similar a fotografia e o desenho, ambos registráveis (BARROCA, 2008; YAN, 2013).

Um outro aspecto que gera dificuldades ao lidar com a questão é a diferença de proteção existente em outros países. Nações como Brasil ou Estados Unidos, participantes da Convenção de Berna - que assegura os direitos de copyright entre os membros -, devem reconhecer juridicamente tipos que possuem o seu design protegido em outros países, mesmo que não ofereçam a mesma proteção legal em seus territórios (DIACRÍTICO, 2016; YAN, 2013). Ainda assim, existem exceções de design protegido, principalmente nos Estados Unidos, que, durante um período, assegurou registros e patentes para typefaces, como as conhecidas ITC Stone, Adobe Garamond e Adobe Minion (figura 5). A lei do país foi alterada anos depois, mas o direito adquirido anteriormente não é prescrito (SCHAFFNER, 1995).

Fig 5. Tipos registrados pelo US Patent and Trademark Office Fonte: $\mathrm{o}$ autor

\section{ITC Stone Serif}

\section{Adobe Garamond} Adobe Minion 
Graham (1999) comenta que, apesar das limitações nas proteções de copyright ou patentes oferecidas aos tipos, muitas empresas protegem os nomes das suas famílias tipográficas pelo registro de marcas. A Monotype, principal empresa no mercado tipográfico, grande produtora e distribuidora de fontes digitais, é detentora dos nomes dos tipos Bembo, Gill Sans, Perpetua e Rockwell, dentre inúmeros outros. No início da era digital na tipografia, muitos de seus tipos foram adaptados e comercializados pela Bitstream com outros nomes, por exemplo Bembo distribuído como Aldine. Houve um acordo entre as empresas quando a Monotype iniciou a digitalização do seu acervo. Contudo, em 1992 outra empresa do mercado tipográfico, a URW, iniciou a comercialização de fontes digitais com nomes muito próximos aos da sua concorrente Monotype. Esta incluíam Bemtus, Gill Kayo, Giltus, Pertus e Rocktus (figura 6). A Monotype entrou com uma ação na justiça alegando violação ao registro dos nomes das suas fontes com a adição de um sufixo -tus ao nome original, sendo a aparência das fontes idêntica aos seus originais já comercializados. $\mathrm{O}$ fato de a URW ter alterado parcialmente o nome comercial não foi suficiente para escapar da condenação, sendo obrigada a arcar com os custos do processo em vista que os nomes usados produziram equívocos no público comprador das fontes digitais (GRAHAM, 19999).

Percebe-se que, no Brasil e em outras nações, apenas o arquivo da fonte digital é protegido pelas respectivas leis de registro de softwares e o seu nome comercial pelas leis de registro de marcas. $O$ aspecto formal dos caracteres tipográficos, enquanto um sistema gráfico, não se enquadram nas interpretações jurídicas, significando que o redesenho analógico de tipos existentes, antigos ou contemporâneos, não é considerado ilegal.

\section{AA $F_{F}$ GG QQ \\ ABCDEFGHIJKLMNOPQRSTUWVXYZ ABCDEFGHIJLLMNOPQRSTUVWXYZ ABCDEFGHIJ
OI 23456789}

\section{Gill Sans Regular}

\section{Giltus Regular}

Fig 6. Comparação entre fontes Monotype e URW: Bembo/Bemtus e Gill Sans/Giltus Fonte: o autor

\section{Apontamentos para o comportamento ético no resgate tipográfico}

Em conformidade com as informações apresentadas anteriormente, indica-se a seguir um conjunto de apontamentos para o comportamento ético no desenvolvimento profissional do resgate tipográfico no design de tipos.

Como enfatizado pelos profissionais e associações, o designer deve observar as leis de propriedade intelectual para que não realize nenhuma forma de infração. Deve levar em consideração a legislação do seu país e, possivelmente, de outros, contemplando sobretudo a origem do design no qual se baseia. É importante destacar que o desenho de tipos existentes em tecnologia pré-digital pode não ter proteção, mas seu nome comercial pode apresentar um registro de marca protegendo 
seu uso. Mesmo que o design dos caracteres tipográficos não seja passível de proteção, a reprodução total ou parcial de tipos contemporâneos para fins comerciais é vista como desrespeito às normas profissionais estabelecidas no setor.

A utilização de uma obra cujo tempo de proteção expirou, encontrando-se em domínio público, não isenta a identificação de sua autoria. 0 direito moral do autor deve ser respeitado sempre, tendo o crédito do original indicado em ficha técnica ou documento de publicação. $O$ uso de obras em domínio público ou sem autoria identificável, deveria se reverter em benefício para a sociedade e a categoria, não apenas em ganho financeiro para a empresa produtora.

Atesta-se que a fonte digital é considerada um software e, consequentemente, protegida pela Lei no 9.609/98. A utilização integral ou parcial dos dados eletrônicos de fontes criadas por terceiros para a produção de uma outra fonte, sem a permissão dos autores, é considerado crime passível de multa e reclusão de até quatro anos.

É importante observar que ao adquirir uma fonte digital o usuário paga por uma licença de uso e não pela posse de um produto em si. 0 detentor dos direitos patrimoniais permite a utilização deste arquivo eletrônico, limitando aplicações ou restringindo usos, de acordo com um termo de licenciamento conhecido como EULA ${ }^{3}$. Contudo, a proteção legal da fonte digital não é estendida ao resultado obtido do seu uso. Deste modo, interpreta-se que, na maioria dos casos, é permitido que o resultado de seu uso seja redesenhado e alterado, de modo analógico ou digital, para uma criação nova. Por segurança, recomenda-se a leitura cuidadosa do termo de licenciamento da fonte digital para se tomar conhecimento das restrições impostas pela empresa ou designer.

Um distanciamento histórico e tecnológico significativo auxilia na definição conceitual do resgate tipográfico, mas, também, favorece o cumprimento das normas de propriedade intelectual em muitos países. Um tipo oferecido em tecnologia muito recente ou que de alguma forma ainda se encontra em uso, provavelmente estará sujeito aos mecanismos de proteção vigentes. Nesses casos, a observância dos termos de licenciamento ou a requisição de permissão documentada dos autores se fazem necessários para a correta atividade profissional.

Nenhum designer deve atribuir apenas para si a autoria de um projeto no qual outros profissionais estão envolvidos, seja por trabalho em equipe ou por meio de apropriação. $O$ resultado obtido na prática do resgate tipográfico pressupõe fidelidade a um design original. Desse modo, também se utiliza da reputação, fama ou qualidade associada a esse original. Qualquer forma de prejuízo gerado no processo de produção e comercialização da nova fonte acarreta em impacto negativo para todos os envolvidos, inclusive para o designer ou empresa responsável pelo original adotado. 


\section{Considerações finais}

Mesmo que o campo do design utilize constantemente de ferramentas e conceitos flexíveis, identifica-se que os designers se preocupam com os preceitos do direito intelectual, juntamente com uma conduta íntegra que represente a categoria profissional na sociedade. Há uma clara consideração pela ética entre os profissionais do design, que se distingue do saber prático e técnico, pois se constitui de valores morais de conduta. Nessa esfera, os códigos de ética, idealizados a partir das experiências no campo, orientam o exercício moralmente correto das atividades profissionais, ainda que não apresentem valor legislativo.

Os apontamentos éticos formulados neste estudo podem oferecer orientações relevantes para os designers de tipos que pretendem realizar a produção de fontes digitais de resgate tipográfico e, talvez, até mesmo fontes de outras naturezas. $O$ resgate, quando realizado com atenção e os cuidados necessários, respeitando-se os aspectos originais e atendendo aos complexos padrões técnicos atuais, resulta em um sério estudo da história da tipografia e uma importante contribuição para a prática contemporânea do design gráfico e de tipos.

10 resgate tipográfico é tema principal apenas nos livros: Revival Type (2017), de Paul Shaw; Type revivals (2011), de Jerry Kelly; Espinosa: rescate de una tipografía novohispana (2005), de Cristóbal Henestrosa; e Revival of the fittest (2000), de Philip B. Meggs.

20 Brasil, os Estados Unidos, a Rússia, o Reino Unido, o México e muitos outros países formam as 175 nações signatárias da Convenção de Berna que reconhece o direito de autor e respeita os aspectos comerciais da propriedade intelectual entre os membros participantes. No Brasil as fontes digitais são protegidas pela Lei no 9.609/98 que regulamenta a proteção específica ao software ou programa de computador. 3 EULA é a sigla em inglês para "Contrato de Licença de Usuário Final" (End User License Agreement), termo de licenciamento de uso das fontes digitais (e outros softwares) no qual se apresentam as permissões e restrições de uso

\section{Referências}

ADG Brasil. Caderno de ética no design. Desenvolvida pela designer Sonia Carvalho. Consultor jurídico da ADG Brasil Dr. Paulo Gomes de Oliveira Filho. São Paulo: ADG Brasil, 2004. ANDRADE LIMA, João Ademar de. Curso de Propriedade Intelectual para Designers. João Pessoa: Editora Novas Idéias, 2006.

ARGAN, Giulio Carlo. Arte moderna: do Iluminismo aos movimentos contemporâneos. Tradução Denise Bottmann, Frederico Carotti. São Paulo: Companhia das Letras, 1992.

Association Typographique Internationale (ATypI). ATypI Statutes. Approved 2004 Minor Revision to the Statutes. Revision4.0. New York: ATypI Board, 2004. 
BARROCA, T. N. Direito e tipografia - Breve incursão sobre o tratamento jurídico das fontes pelo direito brasileiro. In Revista da ABPI. n. 93, março/abril de 2008. Rio de Janeiro: Associação Brasileira da Propriedade Intelectual, 2008. P. 23-34.

CAUDURO, Fálvio V. A retórica visual da pós-modernidade. In Revista FAMECOS. n. 37, dezembro de 2008. Porto Alegre: PPGCOM/PUCRS, 2008, P. 107-114.

CARDINALI, Luciano. Garamond: letras que bailam. São Paulo: Edições Rosari, 2004.

DEVROYE, Luc. ATypI and the Code Morale. Disponível em: <http://luc.devroye.org/ fonts-48608.html>. Acesso em: 24 set. 2017.

DiaCrítico. DiaCrítico 26 - Manoel dos Santos \& Fabio Haag - Registro e licenciamento de fontes.Agosto de 2016. Disponível em:<https://youtu.be/onMTjMO43vs>. Acesso em: 13 nov. 2017. DOWNER, John. Copping an attitude | part 2. In Emigre, n. 38, p.101-9. Sacramento: Emigre Graphics, 1996.

FARIAS, Priscila. Tipografia digital: o impacto das novas tecnologias. Rio de Janeiro: 2AB, 2001. GOMES, Ricardo Esteves. O design brasileiro de tipos digitais: A configuração de um campo profissional. São Paulo: Blucher,2010.

GIANOTTI, Arthur. Moralidade pública e moralidade privada. In Ética. Organização: Adauto Novaes. São Paulo: Companhia das Letras, 1992.

GRAHAM, Lawrence D. Legal Battles that Shaped the Computer Industry. Westport: Quorum Books, 1999.

International Council of Graphic Design Associations (Ico-D). Best practice paper: model code of professional conduct for designers. Montreal: Ico-D, 2011.

LILLIE, Patricia. Arguments against copyright protection of typeface and our responses. In Type Right. 1997-2013. Disponível em: typeright.org/feature3.html. Acesso em: 24 set. 2017. LEBEDENCO, Érico., NEDER, Rafael. Fundamentos do Resgate Tipográfico, In DAT Journal: design, art and technology. Ano 1. Vol. 1. no1. São Paulo: Universidade Anhembi Morumbi, 2016. Disponível em: http://ppgdesign.anhembi.br/datjournal/index.php/dat/article/ view/12/7. Acesso em: 13 nov. 2017.

NOVAES, Adauto. Cenários. In Ética. Organização: Adauto Novaes. São Paulo: Companhia das Letras, 1992.

LO CELSO, Alejandro. A discussion on Type Revivalism, In MA in Typeface Design. Reading: University of Reading, UK, 2000.

POYNOR, Rick. Abaixo as regras. Tradução: Mariana Bandarra. Porto Alegre: Bookman, 2010. ROCHA, Claudio. Novo projeto tipográfico. São Paulo: Edições Rosari, 2012.

SCHAFFNER, Paul F. Copyright and Digital Typography. 1995. Disponível em: www.personal. umich.edu/ pfs/essay2. Acesso em: 24 set. 2017.

SMEIJERS, Fred. A new moral code. In Type Now - a manifesto. London: Hyphen Press, 2003. SOTA. DMCA Policy. Disponível em: www.typesociety.org/about/dmca/. Acesso em: 26 nov. 2017. VANDERLANS, Rudy. Copping an attitude | part 1. In Emigre, n. 38,p.6-9. Sacramento: Emigre Graphics, 1996.

VILLAS-BOAS, André. O que é [e o que nunca foi] design gráfico. Rio de Janeiro: 2AB, 2007.

YAN, Jack. The Legal Side. In Type Right. 1997-2013. Di sponível em: <http://typeright.org/ feature4.html>. Acesso em: 24 set. 2017. 